\title{
Cultural Values and the Decision to Circumcise
}

Chandice C. Harris

Circumcision is no longer recommended by the American Academy of Pediatrics. However, in the United States, circumcision still prevails. This paper reports a qualitative research study that identifies variables which influence the decision to circumcise the male newborn. A cultural decision-making model is presented that predicts and explains decision-making pathways taken by individuals. The value of this model lies in the opportunity for the nurse to assess and intervene based on client knowledge as well as cultural values.

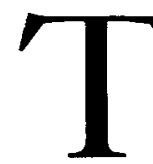

hat it is right and proper to be circumcised is an assumption of the dominant American culture. The majority of males born are circumcised before they leave the hospital, even though in 1975 the American Academy of Pediatrics reaffirmed the stance:

There is no absolute medical indication for routine circumcision of the newborn . . . circumcision of the male neonate cannot be considered an essential component of adequate or total health care. (p. 610).

The Academy's edict along with research that demonstrates the fallacy of the procircumcision argument makes circumcision at best a questionable health practice and at worst a costly, life-threatening ritual. Even more important are the cultural processes that influence the circumcision decision and serve to "disenfranchise" males based on the presence of a foreskin.

Circumcision is the most frequently performed surgical procedure in the United States. Currently, in the U.S., 80 to 90 percent of newborn males are circumcised (Wirth, 1980), though Wiener (1980) reports a low of 30 percent for infants born at home or in alternative birth settings. Still, these rates far surpass those in other countries where circumcision is viewed as being unnecessary, for example, in Canada, England and Sweden (Wirth, 1980). This study addresses the research question, "What variables influence parents' decisions to circumcise or not to circumcise their newborn?",

\section{Background}

In 1859 Florence Nightingale (1859/1970) promoted the idea that nursing is concerned with discovering and reinforcing nature's "law of health" (p. 60). One such "law of health" is that the uncircumcised state is a natural, not pathologic, condition. There now exists ample scientific evidence to discard the idea that circumcision is a health practice. Not so clear are the cultural processes that influence the social need for circumcision. Because maternal-child nursing practice requires teaching and counseling clients about their circumcision choice along with assisting with the procedure, scientific as well as transcultural enlightenment of the nurse is necessary (Harris \& Stern, 1981).

At present many health professionals act as "cultural imposers" by denying circumcision to some subcultures who desire the procedure and by promoting circumcision to others who are uncertain as to the need for the procedure (Aamodt,

Chandice C. Harris, R.N., M.S.N. Beta Chi, is a doctoral student at the School of Nursing, University of Michigan. Correspondence to 2345 Stone, Ann Arbor, MI 48105.

This article is slightly edited and reprinted, with permission of the publishers, from P. N. Stern (Ed.) (1986). Women, health and culture. New York: Hemisphere Publishing Corporation. The author thanks Dr. Phyllis Stern for her assistance in the development and realization of this research project. 
1978; Leininger, 1979). In fact, many doctors and nurses in the study asked, "Why research circumcision? It's such a little thing . . . " (no pun intended). This "little thing" acts as an additional stressor, especially during the postpartum period, when parents are trying to make a decision that they feel will affect their child for a lifetime. Furthermore, Dickoff, James, and Semradek (1975) suggest that "Nursing reality from the consumer's view point is a madhouse world of horrors" (p. 86). They propose that nursing research be evaluated as to "payoff," that is, research in nursing that results in improved patient care processes in the health care system.

\section{Review of the Literature}

Around the turn of the century the status of circumcision changed from a religious rite to a common surgical procedure. In 1891, a physician, Remondino (1891/1974) stated that the foreskin was a "dangerous relic of a far-distant prehistoric age," designed to protect unclothed early man from "bark, brambles, and insect bites"' (p. 34).

The five main reasons for circumcision include (a) an adolescent initiation rite of passage and test of manhood through torture and pain, (b) a personal sacrifice in religious ritual, (c) an act to mark, torture and humiliate slaves and defeated warriors, (d) conformity with hygienic and cosmetic values, and (e) a response to the antimasturbation hysteria of the late 1800 s (that is, if the child has to wash under the foreskin, he might learn to masturbate). Even today many of these reasons are used but with a slightly different context in language and custom. Woven through the history of circumcision is ritual, psychoanalytic theory and stigma.

Ritual

Rituals are rich in symbolism. The symbolism of circumcision hinges on the absence of a foreskin, which implies that more than a simple operation has taken place. Especially in America, it suggests that a well-accepted "ritual" has occurred. The term "ritual," according to Gluckman (1975), is used to describe many different kinds of phenomena of a repetitive, almost obsessive nature. When approved by a certain culture, ritual can become standardized, repetitive and prescribed; that is, cultural rules command that the ritual be performed. Such rules were especially evident in past years when hospitals routinely circumcised newborns, often without informed parental consent.

Most rituals signify a rite of passage and convey a sense of belonging. When a culture accepts a ritual of another culture, it signifies a desire for status passage, or "keeping up with the Joneses." In the United States, "the Joneses" are the norms, beliefs and values of the dominant American culture (Glaser \& Strauss, 1971); this includes the tradition of circumcision.

\section{Psychoanalytic Theory}

Another aspect of circumcision is embodied in the Freudian theory of psychologic processes existing between the mother, child and father. Shrouded in misogyny, these suppositions explain circumcision as a ritual of matriarchal control, a measure to resolve the Oedipal conflict and a symbolic solution to man's envy of the wormb and fear of that envy (Bettelheim, 1954; Gluckman, 1975; Kitahara, 1976; Ostow, 1970).

\section{Stigma}

In subtle and overt ways the uncircumcised male is stigmatized by the dominant American culture. Fear of stigma leads American parents to elect circumcision. As Cogan (1981) points out, the American Academy of Pediatrics did not offer any guidelines on the management of cultural pressures and potential identity problems generated in the locker room or in the family system because of this stigma.

Clearly, the brunt of the stigma is experienced by the child, not by the parents who made the choice. In the words of one of my chief informants, who is an uncircumcised urban white, "I think there is psychological trauma when you are not circumcised. I went through gym class, being in the locker room. There were not remarks, but I felt different." But not all uncircumcised men who were interviewed felt this way. Some related a feeling of superiority, that they possessed something better than being circumcised. Goffman (1963) in Stigma, explains this attitude:

It seems possible for an individual to fail to live up to what we effectively demand of him and yet be relatively untouched by this failure; insulated by his alienation, protected by identity beliefs of his own, he feels that he is a full-fledged normal human being, and that we are the ones that are not quite human. (p. 6)

Those uncircumcised males or parents of uncircumcised males who feel stigmatized by the dominant American culture, Goffman suggests further, may attempt to "cover," or restrict the display of the stigma, similiar to the person undergoing a rhinoplasty or mammoplasty. The usual situation is the "circumcision rider" attached to another surgical procedure. Examples of this include the 4-year-old who receives a circumcision along with a tonsillectomy or the 40-year-old who is circumcised along with a vasectomy. What often results is the absence of a fully formal status; that is, a circumcised male but one who is, according to Goffman, "someone with a record of having corrected a particular blemish" (p. 102). It is the old horror story. "He had to be circumcised at 40 !",

Major influences on the development of the foreskin stigma are the myths that make circumcision a necessity. Research exposes these myths, yet the findings are neither well distributed nor accepted by the dominant American culture. Concisely, these findings are summarized as follows, (Harris \& Stern, 1981):

1. Newborns are born with fused foreskins.

2. The foreskin gradually separates. Complete separation may not occur until near puberty.

3. Smegma is most often nonexistent in children.

4. Forced retraction of the foreskin (often done by caretakers) produces scar tissue.

5. Scar tissue produces adhesions.

6. Adhesions make circumcision necessary (a "Catch 22"' situation).

7. Cancer of the prostate, cervix, and penis is directly related to personal hygiene, not to the presence or lack of a foreskin.

\section{Methodology}

This study was conducted using a naturalistic approach to develop grounded theory. According to Stern (1980), qualitative research is particularly useful when a new perspective on a familiar situation is needed. Especially in America, the circumcision of newborns is a familiar situation. However, a new perspective is now needed because of the American Academy of Pediatrics' stance on circumcision.

\section{Data Collection}

The majority of the data represent approximately 60 hours of participant-observation study in north Louisiana. The 
interviews were conducted at numerous sites and times at the convenience of the subjects. At first, the interviews were open free-flowing; as the process emerged they became more directed. The interviews were written down verbatim and later typed for analysis.

\section{Sources of the Data}

Initially the sources of the data were new parents, nursery nurses and pediatricians. As the processes of the theory emerged, theoretical sampling included pregnant women and couples, parents of older children, urologists, obstetricians, general practitioners, pediatric nurse practitioners, community health nurses, certified nurse midwives and men and women of various ages. The literature, additionally, provided an important source of information.

It is important to emphasize that the data from the grounded theory approach is qualitative, not numerative, with hypotheses generated but not tested. Therefore demographic data, personality factors and intelligence quotients are not relevant to the study.

\section{Data Analysis}

With grounded theory, analyzing the data is a constant, comparative, cognitive process similiar to a matrix computer-analyzed design; that is, each datum is examined in reference to all other data and to the emerging categories and processes. As themes are discovered, further data collection serves to strengthen and refine these themes. According to Wilson (1977), data are interrelated for "causes, contexts, contingencies, consequences, covariances, conditions, mutual effects, cutting points, degrees, and types"' (p. 109). The resultant hypotheses yield a molecular rather than a direct causal relationship. The theorists of grounded theory, Glaser and Strauss (1967), refer to this as a "dense" theoretical schema. The credibility of this resultant schema is advanced by the "goodness of fit" that the theory has for the real world. Glaser (1978) claims that it is the "integration, relevance and workability' of the theory that promotes its significance.

\section{Findings}

In this study, the substantive area is circumcision of newborns under conditions existing in the lay and health culture. The categories named circumcision reasoning, cultural

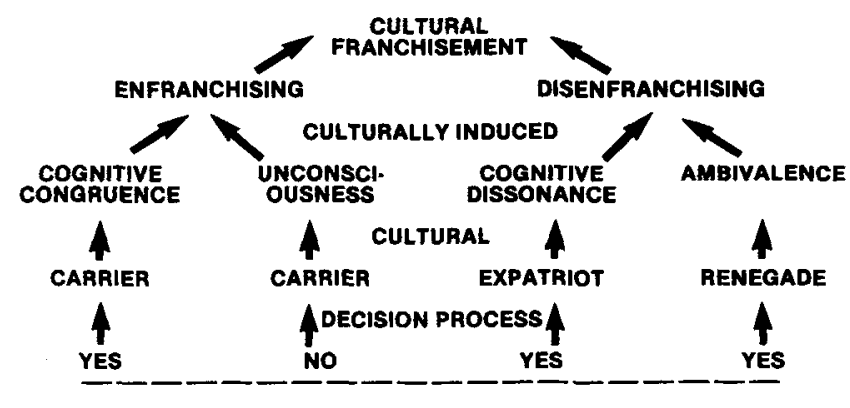

DECISION COMPONENTS

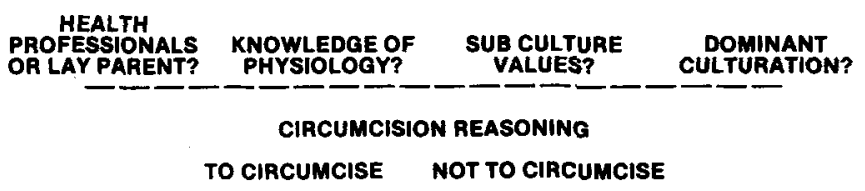

Figure 1. Components of circumcision reasoning. decisionmaking and cultural franchising were discovered and are shown in Figure 1.

\section{Circumcision reasoning}

The major reasons to circumcise one's child are balanced out by the same reasons to avoid circumcision; for instance, the reason "medical advice" is used in both instances. However, the way in which these reasons are defined by the parent differs markedly from family to family and culture to culture. MacKay (1978) explains that cultural patterns are designs not only for reality perceptions, but also for constructing that reality. The subjects in the present study gave evidence of how they had constructed their reality through their reasons for and against the practice of circumcision. Their answers were categorized into nine main reasons and are shown in Figure 2. The emphasis of this report focuses on these reasons for choosing circumcision.

Sign of manhood. The most common reason to circumcise was "So he will look like his daddy (or brother)." An additional theme in this line of reasoning was explained by one father's words, "Even if it hurts, he has to go through it . . . One day he'll thank me." It was interesting to observe the strong emotion evoked, especially in the Anglo male, when he was told that circumcision was no longer recommended. As one informant stated, "It's part of being a man in a man's world . . . My father was circumcised, I am, and my son will be." This need for circumcision as a sign of manhood was reflected in the words of one of the chief informants, "Men are put down by those who have [been circumcised]. All males should be; then they have things in common."

Culturally induced unconsciousness. The existence of culturally caused or induced unconsciousness was evident in the data (Aamodt, 1978). Such reasoning was "You don't stop to question what has always been done" and "We didn't even talk about it, we just assumed it would be done." Most parents are never in a position to think about, discuss or question circumcision. There is no need. The child will be circumcised, period.

\begin{tabular}{|l|l|}
\hline \multicolumn{2}{|c|}{ CIRCUMCISION REASONING } \\
\hline \multicolumn{1}{|c|}{ To Circumcise } & \multicolumn{1}{c|}{ Not To Circumcise } \\
\hline 1. Sign of manhood & 1. Sign of manhood \\
2. Culturally induced & 2. Culturally Induced \\
unconsciousness & \multicolumn{1}{c|}{ unconsciousness } \\
3. No harm, no pain & 3. Traumatic / dangerous \\
4. Sex worries & 4. Sex worries \\
5. Hygienic / cosmetic / comfort & 5. Hyglenic / cosmetic / comfort \\
6. Guidance from Bible & 6. Guidance from Bible \\
7. Playing it safe & 7. Playing it safe \\
8. Cultural / sentimental order & 8. Cultural / sentimental order \\
9. Medical advice & 9. Medical advice \\
\hline
\end{tabular}

Figure 2. Balance of factors In clrcumcision reasoning.

No harm, no pain. As one informant stated, "There are less problems if it's done early. It's bad on a grown man. It can cause him to have problems with sex." Or as another said, "It's better to do it when they're a baby, it doesn't hurt." And, "There are no nerve endings. Babies don't feel it like a grown man does."

Contrary to these beliefs, research demonstrates that during and following circumcision, newborns show behaviors that when observed in an adult are diagnosed as pain. These include crying, changes in sleep-wake states and feeding patterns and significant increases in the endocrine response (Anders \& Chalemian, 1974; Talbert, 1976). However, since 
newborns are unable to verbalize this distress, even some health professionals believe that pain is not experienced during the procedure.

The issue of harm to the newborn is also usually denied. The fact is that 1 out of 500 circumcisions threatens the life of the neonate; while few (less than two per million procedures) actually result in death. However, these numbers are being challenged as a result of the connection between circumcision and neonatal sepsis, a leading cause of neonatal death (Cogan, 1981; McHugh, 1981).

Indeed males who undergo circumcision later in life report marked physical and psychologic suffering. It is postulated, however, that this response occurs because in America, adult circumcision is a mistimed cultural event. Ozturk (1973) reports that in Turkey, children between three and seven years of age are circumcised without anesthesia. Contrary to the predictable psychologic effects of the operation at this age, namely castration anxiety, Ozturk discovered that the societal preparatory experience and meaning overrode such effects. The dominant American culture ignores, exaggerates or makes this experience the brunt of jokes. Meanwhile it is interesting that a similar invasive procedure, female episiotomy, has not (until recently) received the notoriety of adult male circumcision. Whether this is because of a woman's "long-suffering role" or the cultural sanction of episiotomy is not clear.

Sex worries. Frequently mentioned reasons for advocating circumcision referred to sexual concerns, both for the adult sexuality of the child and his relationship to his mother and father. Circumcision was viewed most often as a method of preventing masturbation or promiscuity in sexual matters. One father stated, "It will make it last longer." A mother related, "I had him circumcised when he was two because he started playing with himself." And from another, "Men who are circumcised are able to control themselves; it prevents premature ejaculation." It is interesting that a similar operation, female circumcision, is prescribed in America for the opposite effect, namely to cure frigidity (Wollman, 1974). Conversely, in Egypt, female circumcision is practiced to attenuate the female sexual response (Assaad, 1980).

The idea of sex also concerned the mothers who were then caring for their sons. As best explained by one female informant, "The child might remember his mother cleaning under the foreskin. Mother has no business doing that." This theme, found across cultures, exposes the fear of incest attached to the uncircumcised state.

Hygienic, comfort and cosmetic. The argument for circumcision for reasons of hygiene, comfort and "beauty" is greatly supported by the dominant American culture. First, hygiene can be a problem, especially for individuals who do not practice adequate hygiene either because of cultural factors or because of lack of bathing facilities and supplies. As one 56year-old male informant explained, "We took a bath a week and you best not be caught washing below the water line. And Mom certainly didn't [help with hygienic care]. It wasn't right."

War-associated conditions were also mentioned by some informants: the lack of opportunity to cleanse the body during World War II or the Korean and Vietnam conflicts. However, one urologist interviewed claimed that circumcised males suffer equally in such circumstances because of irritation of the glans and of the perineal area in general.

The need for hygiene relates to the occurrence of smegma. Smegma is composed of both a lubricating fluid secreted by the glands of the inner surface of the prepuce (or clitoral hood) and desquamated epithelial cells. This composition has been implicated as being carcinogenic; however, recent studies have failed to demonstrate this causal relationship. It is important to point out that women also produce smegma.

Nurse informants discussed the poor hygiene practices of elderly males. As one said, "A man of 70 is not worried about cleaning himself." Elderly females suffer some of these same problems, but with more available female caretakers, female hygienic care is provided without the taboo associated with a female nurse caring for a male.

Comfort reasons included the idea that a "tight" foreskin "bothered" the child. One mother stated that as her son was toilet training, he would "grab at his penis" when he needed to urinate. This she attributed to a "tight skin." However, even after circumcision, the child continued this behavior until full bladder training was achieved.

Finally, the cosmetic appeal of circumcision is best explained as "beauty being in the eye of the beholder." In America, the beholder is the dominant culture that has advanced the notion that the circumcised penis is more aesthetic. It is as Leitch (1970) states, "The exposed glans is the fashion" (p. 59). However, in other countries, circumcision is viewed as a barbarous practice that leaves the male disfigured. This is much the same view that an American might have toward female circumcision practiced in other cultures.

On an historical note, the Greeks (A.D. 14-37) in their quest for Christianity, balked at the rabbinical direction to undergo circumcision. To meet a consumer need, a "decircumcision" procedure was developed to reconstruct the prepuce after the Greek male was circumcised. This need related to the Greek's love of the natural beauty of the human body (Rubin, 1978).

Guidance from the Bible. Many informants cited the teachings of the Bible as their motivation for circumcision. One informant stated, "My mother regretted not having my four brothers circumcised. She believes from the Bible... Boy babies having to be [circumcised] or they're unclean. She worries about what the Bible said. She prays for my brothers to go to heaven anyway."

The Jewish biblical heritage of the covenant of circumcision addresses the chosen people:

And God said unto Abraham . . This is my covenant, which ye shall keep, between me and you and thy seed after thee; Every man child among you shall be circumcised . . . And the uncircumcised man child whose flesh of his foreskin is not circumcised, that soul shall be cut off from his people; he hath broken my covenant (Gen. 17:9-14).

One can appreciate the importance of the act to the Jewish people. This covenant has been a source of confusion, especially when interpreted to apply to individuals not of the Jewish faith. The circumcision law was recorded in the Bible when the Jews suggested that the lack of circumcision among the Gentiles excised them from the faith. Apostle Paul's advice in the New Testament cleared up this concern:

And put no difference between us [the Jews] and them [the Gentiles], purifying their hearts by faith (Acts, 15:9).

Is any man called [to the faith] being circumcised: Let him not become uncircumcised. Is any called in [to the faith] uncircumcised: Let him not be circumcised (I Corinthians, 7:18).

These passages implied that God wanted evidence of faith, not merely circumcision, from the Gentiles-the concept of "circumcision of the heart." It is interesting, then, that one 
of the main reasons given by parents today who are not Jewish is, "It says to do it in the Bible, doesn't it?"

Playing it safe. Some parents elect to have their sons circumcised even when they are uncertain as to the need. This need to "play it safe" was evident when one mother stated, "I know that it's not needed, but I worried. I decided to have it done just in case something went wrong." There are many other examples of "playing it safe," for example, infant baptism by agnostic parents or an educated woman who is careful not to raise her hands above her head during pregnancy. Playing it safe allows the individual to "ward off" danger or bargain with fate: "If I have my son circumcised, he won't have problems." This reasoning is closely associated with the next reason-sentimental order.

Cultural sentimental order. Sentimental order is an emotional attachment to familiar ways of doing things (Stern, 1982). Sentiment compels one to ascribe. For example, one couple interviewed was on the waiting list to adopt a boy baby. In this area the relinquished infant is circumcised before his adoptive parents are notified. Since this adoptive father had not been circumcised and was adamantly against circumcision, the couple changed their preference to a girl baby.

Health professionals also "suffer" from the effects of sentimental order. One pediatrician, whose spouse was pregnant, said, "I don't know what I'll do if it's a boy. It just seems right to circumcise my son, even though I know it's not necessary to do it." Some of the health professionals, to save professional "face," placed responsibility on the spouse for electing circumcision for their son. In fact, all of the pediatricians interviewed stated that they were against circumcision; and yet their children were circumcised.

Meeting one's sentimental order through circumcision provided comfort to parents and their friends and relatives. Failure to experience this sentimental order led to such associated feelings as uneasiness, guilt, regret, grief and a sense of courting diaster.

Medical advice. While no longer advocated by the Academy, circumcision is still valued very much by some physicians and nurses. One nurse interviewed stated, "I encourage all my friends to have it done when they have a boy. It solves a lot of problems." Some general practitioners, obstetrician-gynecologists and urologists interviewed supported either circumcision or forced retraction. As one general practitioner stated, "You have to free the foreskin, then teach the mother to keep it back. But some women just won't do it. So the baby has to be circumcised later." However, forced retraction is not a therapeutic intervention. The two opposing epithelial surfaces tend to seal together following forced retraction and adhesions form (Harris \& Stern, 1981).

Many health professionals interviewed mentioned parent and staff pressure to have the circumcision performed. As one physician said, "The nurse is my worst enemy on this. I get the parents agreeing not to have it done, and before I can get back to my office the nurse has talked them into wanting it again. So it's just easier to go ahead and do it." A nursemother of boys informed me of intense pressure from her obstetrician to have the circumcision done. "I really had to stand my ground on this," she reported. Health ethnocentrism, which is the health professional's belief that their factual and value systems are always correct, frequently governs medical advice (MacKay, 1978). In the case of circumcision, many professionals do not accept the findings that eliminate the need for the procedure. As a urologist stated, "I've never seen a circumcised man with penile cancer. They can't tell me it [circumcision] doesn't prevent cancer."

The reasons to circumcise are varied and have different meanings for each individual parent. None of the reasons are based on fact. Value systems and cultural beliefs form the framework of the reasons.

\section{Cultural Decision-Making Process As Cogan (1981) suggests:}

Whatever its origin and meaning, circumcision represents a difficult area of decision-making for many prospective parents today, except where unambiguous cultural tradition facilitates decision-making (p. 1).

Most parents experience a decision-making process that hinges on four main states of nature: (a) Is the parent a health professional? (b) Does the parent understand the physiology of the foreskin? (c) Does the parent's subculture value circumcision? (d) Does the parent value and ascribe to such dominant American culture prescriptions as circumcision? This process is depicted in the cultural decision-making model in Figure 3.

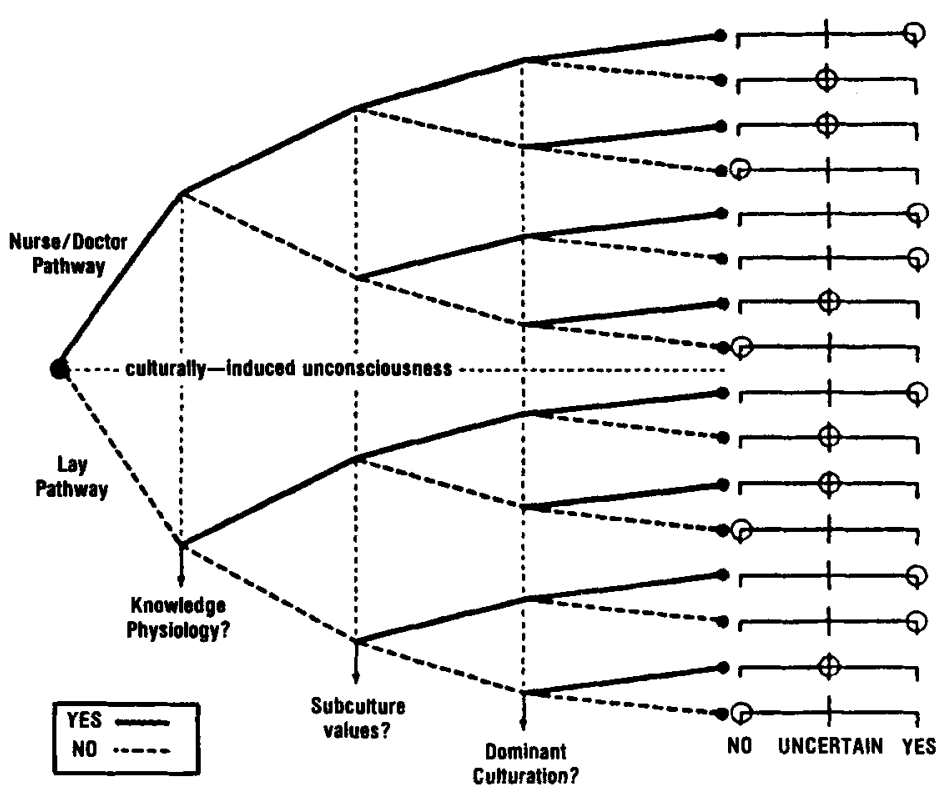

Figure 3, Cultural decision-making model.

Figure 3. Cultural decision-making model.

To use the model, the health professional first determines whether the parent is a lay person or is affiliated with a health profession. Second, knowledge about physiology of the prepuce as well as about myths is assessed. When given such information, many parents in the present study were surprised, and it made the decision more difficult. Knowing does not assure the valuing of such information. As Aamodt (1978) states, "Common sense ways of acting on health and healing situations may appear either to be related or unrelated to a cultural belief system"' (p. 10).

Third, the subcultural beliefs about circumcision are determined. Groups such as the American Indians and Hispanics have not traditionally practiced circumcision; therefore it is not part of their sentimental order. Similar to an ethnic subculture is what Stern (1982) describes as "individual family culture" - the nuclear and extended family's unique sentimental orders and cultural heritage. While a parent may be part of the dominant American culture, there are special influences from individual family cultures. 
Finally, the parent's relationship to the dominant American culture is assayed. Valuing the dominant American culture's prescription in general implies cultural change or acculturation of the subculture parent.

By tracing the pathway through determination of lay status, knowledge, myths, and culture influences, one arrives at a decision to circumcise, a decision not to circumcise, or uncertainty over the decision. The model predicts the decision-making pathways that individuals take in response to the described determinants. The value of this model lies in the opportunity that it affords health professionals to assess as well as intervene based on client knowledge and cultural values.

\section{Cultural Franchise}

As the research process in this study advanced, the construct of cultural franchising (see Figure 4) became evident. Parents who elected to have their sons circumcised were accepted, or "franchised," by the dominant American cultural network of family, friends, associates and even health professionals. Those who resisted or did not follow the cultural network were pressured and criticized, or "disenfranchised." Some sought later circumcision for their child to relieve these pressures.

The outcomes of the decision to circumcise or not to circumcise led to a classification of three main archetypical cultural actors:

1. The cultural carrier. One who follows and promotes cultural norms (Aamodt, 1978), for example, the urban white.

2. The cultural expatriot(ate). One who is denied access to practice cultural norms, for example, the indigent Southern Black.

3. The cultural renegade. One who purposively does not practice cultural norms, for example, the Hispanic or naturalist parent.

The decision of these actors invoked feelings either of cognitive congruence, dissonance or ambivalence. Congruence is simply agreement between cultural norms and actions. Dissonance implies nonagreement between cultural norms and actions, along with such associated feelings as uneasiness, guilt, regret and a sense of courting disaster. Finally, ambivalence is the alternating emotion of being drawn to, yet at the same time, repelled by cultural norms and actions.

In response to the circumcision choice, the parent and child are enfranchised or disenfranchised by their subculture as well as by the dominant American culture. The franchise is

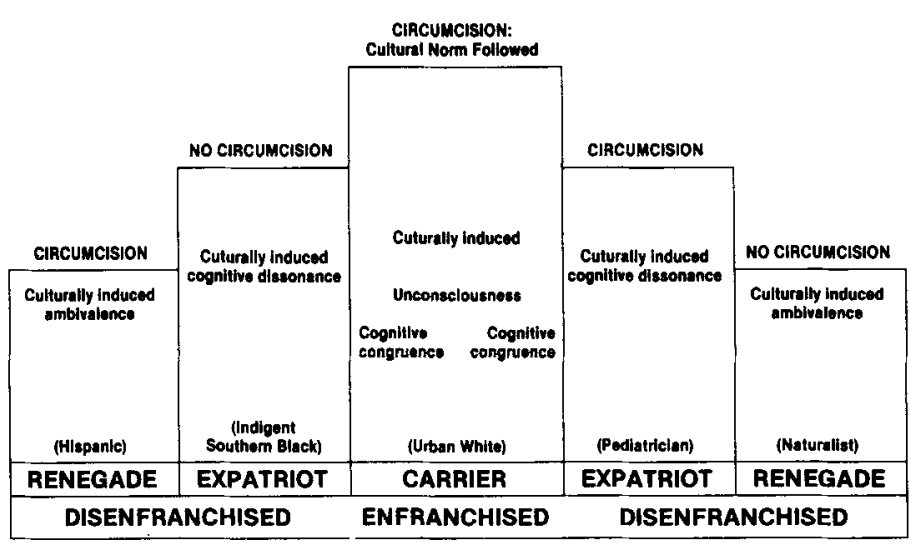

Figure 4. Critical junctures of franchisement. cultural credibility; it may be described as a cultural credit card-the "American Express" in the locker room. The best example of this disenfranchised process was given by a circumcised Anglo father who elected not to have his son circumcised:

When we brought the baby home, my neighbor came over and noticed during a diaper change that my son was not circumcised. He asked me about it. When I told him that we had decided not to have him circumcised, he gave me all the reasons why we should. He said, "Only poor black and farm boys aren't." Once he saw that his pleading was doing no good, he got angry and left.

The two main processes of the Cultural Franchise theory, then, are (a) enfranchising, or the process of extending cultural credibility in response to acceptable behaviors and attitudes, and (b) disenfranchising, the process of denying this cultural credibility when cultural norms are not observed.

\section{Conclusion}

A transcultural health setting is defined by Aamodt (1978):

one in which health professionals and clients informed by different cultural, health, and healing systems communicate and resolve their differences in order to meet the needs of the client (p. 9).

As demonstrated in this study, those needs vary in regard to circumcision.

Two clear stances guide client care. One is in Zimmer's (1977) words: "When a physician disagrees with the parents on performing the operation but goes along with their decision, this is not medical leadership" (p. 505). This viewpoint directs health professionals to inform parents and encourage them strongly not to have their child circumcised and even not to offer the procedure.

The second viewpoint allows a less rigid alignment with scientific knowledge; that is, circumcision is an acceptable practice based on cultural values. As Leininger (1979) suggests:

Ritualized ethno-caring activities can have highly therapeutic benefits to clients and their families and should not be readily modified or disbanded as "too routine" and "nontherapeutic" caring measures (p. 24).

Therefore, since circumcision is a relatively safe practice, culture might be the deciding factor. The teaching, anticipatory guidance and actual procedure must be in tune with "cultural boundedness," namely the "relationship between a cultural system and a cultural carrier" (Aamodt, 1978, p. 8). In this way, the health professional is a caring and perceptive cultural broker. The assessment needed to provide this harmony can be completed using the described cultural decisionmaking model.

The theory of the cultural franchise is grounded in the experience of parents, health professionals and the child. Finally, a major discovery of this study was that the truly disenfranchised individual is the circumcised son of the enfranchised parent. He has no options and no freedom to change his state.

\section{References}

Aamodt, A. (1978). Culture. In A. Clark (Ed.), Cultural-childbearing-health professionals. Philadelphia: Davis.

American Academy of Pediatrics (1975). Report of the ad hoc task force on circumcision. Pediatrics, 56, 610-611.

Anders, T., \& Chalemian, R. (1974). The effects of circumcision on sleep-wake states in human neonates. Psychosomatic Medicine, 36, 174-179.

Assaad, M. (1980). Female circumcision in Egypt: Social implications, current research, and prospects for change. Studies in Family Planning, 11(1), 3-16. 
Bettelheim, B. (1954). Symbolic wounds: Puberty rites and the envious male. New York: Free Press.

Cogan, R. (1981). Circumcision. ICEA Review, 5(1), 1-7.

Dickoff, J., James, P., \& Semradek, J. (1975). 8-4 Research, Part I: A stance for nursing research-Tenacity or inquiry. Nursing Research, 24(2), 84-88.

Glaser, B. (1978). Theoretical sensitivity. Mill Valley, CA: Sociology Press.

Glasser, B., \& Strauss, A. (1967). The discovery of grounded theory: Strategies for qualitive research. Chicago: Aldine.

Glaser, B., \& Strauss, A. (1971). Status passage. Chicago: Aldine.

Gluckman, M. (1975). Specificity of social-anthropological studies of ritual. Mental Health society, 2, 1-17.

Goffman, E. (1963). Stigma: Notes on the management of spoiled identify. Englewood Cliffs, NJ: Prentice-Hall.

Harris, C., \& Stern, P. (1981). Care of the prepuce in the uncircumcised child: Reinforcing nature's law of health. Issues in Comprehensive Pediatric Nursing, 5(4), 233-242.

Kitahara, M. (1976). A cross-cultural test of the Freudian theory of circumcision. International Journal of Poychoanalytic Psychotherapy, 5, 535-546.

Leininger, M. (1979). Transcultural nursing. New York: Masson.

Leitch, I. (1970). Circumcision: A continuing enigma. Austrian Pediatrics, 6, 59.

MacKay, S. (1978). Cultural factors as a source of influence on the health professions. In M. Hardy \& M. Conway (Eds.), Role theory: Perspectives for health professionals. New York: Appleton-Century-Crofts.

McHugh, M. (1981). Circumcision: Is it ever necessary? Irish Medical Journal, 74(2), 55-56.

Nightingale, F. (1859/1970). Notes on nursing: What it is, and what it is not (2nd ed.). London: Duckworth.

Ostow, M. (1970). 'Parent's hostility to their children. Isracl Annals of Psychiatry and Related Disciplines, 8(1), 3-21.

Ozturk, O. (1973). Ritual circumcision and castration anxiety. Psychiatry, 36, 49-59.

Remondino, P. (1891/1974). History of circumcision from the earliest time to the present. Philadelphia: Davis \& AMS.

Robin, J. (1978). Celsus' decircumcision operation: Medical and history implications. Urology, 16 (1), 121-124.

Stern, P. (1980). Grounded theory methodology: Its uses and processes. Image, 12(1), 20-23.

Stern, P. (1982). Conflicting family culture: An impediment to integration in stepfather families. Journal of Psychosocial Nursing, 20(10), 27-33.

Talbert, L. (1976). Adrenal cortical response to circumcision in the neonate. Obstetrics Gynecology, 48, 208-210.

Weiner, R. (1980). Circumcision. Mothering, 16, 35-40.

Wilson, H. (1977). Limiting intrusion-social control of outsiders in a healing community: An illustration of qualitative comparative analysis. Nursing Research, 26(2), 103-111.

Wirth, J. (1980). Current circumcision practices: Canada. Pediatrics, 66(5), 705-708.

Wollman, L. (1974). Female circumcision. Journal American Society Psychosomatic Medicine, 20(4), 130-131.

Zimmer, P. (1977). Modem ritualistic surgery. Clinical Pediatrics, 16(6), 503-506

\section{Gall for Abstracts}

Menstrual Cycle Research Conference-Call for Abstracts-The program "SEXUALITY AND THE MENSTRUAL CYCLE: CLINICAL AND SOCIOCULTURAL IMPLICATIONS," will be held June 4-6, 1987 in Ann Arbor, Michigan. Submission deadline December 1, 1986. For details contact: S. DeGroote, Program Coordinator, Center for Nursing Research, University of Michigan, Ann Arbor, MI 48109-0482, (313) 747-0352.

Call for Abstracts-15th Annual Nursing Research Conference-September 17-18, 1987, The University of Arizona College of Nursing. A three to five page summary of your research should be sent by March 1, 1987 to: Program Subcommittee Chairman, 15th Annual Nursing Research Conference, College of Nursing, The University of Arizona, Tucson, Arizona 85721.

Call for Abstracts-Clinical, educational, and administrative research abstracts are being accepted for Christine L. Oglevee Research Papers Day on April 23, 1987. Sponsored by the University of Mississippi School of Nursing, the Medical Center Division of Continuing Health Professional Education, and the Theta Beta chapter of Sigma Theta Tau. Deadline for submission is November 14, 1986. Contact Jan M. Evers, RN, MN, Associate Dean for Continuing Education, School of Nursing, University of Mississippi Medical Center, 2500 North State, Jackson, MS 39216-4505, or (601) 984-6208.

\section{Call for Abstracts}

\section{INTERNATIONAL RESEARCH CONFERENCE} EDINBURGH, SCOTLAND, July 29-30, 1987.

Clinical Excellence in Nursing: International Networking

Sponsored by The Royal College of Nursing Research Society, The Department of Nursing Studies of the University of Edinburgh, and Sigma Theta Tau, International Honor Society of Nursing.

The theme of the conference encompasses both scholarship in nursing and international cooperation. In addition to research papers, contributions are sought about other issues which are relevant to the attainment of scholarship, to the pursuit of clinical excellence in nursing, and to the improvement or maintenance of international cooperation.

ABSTRACTS of completed or ongoing scholarly work are invited for consideration. Poster presentations, as well as papers, will be included in the conference. A poster presentation, which offers increased opportunities for collegial exchange, is particularly appropriate for projects which can be summarized in a visual display.

CLOSING DATE for receipt of abstracts in NOVEMBER 30, 1986. Acceptance notifications will be mailed by March, 1987 .

FOR SUBMISSION, abstracts should be in English and typedsingle-spaced ( 500 words maximum).

ABSTRACTS of RESEARCH PROJECTS should contain:

- title of paper and author(s)

- purpose and objectives

- significance of the research problem

- research methods including design, sample, procedure, measurement and data analysis

- summary of results of analysis (if not complete, indicate expected date of completion)

- implications for nursing practice

ABSTRACTS on RELATED ISSUES should contain:

- title of paper and author(s)

- nature of the discussion and central thesis

- relevance to the main conference theme

- significance for nursing scholarship and practice

A COVER SHEET accompanying each abstract should contain:

- title of presentation

- author(s) names and credentials/qualifications

- present employment and work location

- full address

- telephone number for home and work

- preference for paper or poster presentation (if paper, 20 minutes for presentation)

SEND abstract and cover sheet by November 30,1986 to: (from North and South America, India and Asia)

Program Office

Sigma Theta Tau,

International Honor Society of

Nursing

1100 Waterway Blvd.

Indianapolis, IN 46202

USA

Phone: (317)634-8171 (from UK, Scandinavia, Europe, Middle East and Africa)

\section{Conference Organizer}

Royal College of Nursing

Scottish Board

44 Heriot Row

Edinburgh EH3 6EY Scotland

UNITED KINGDOM

Phone: (031)225-8231

\section{Symposium}

Legacy from the Past-Agenda for the Future-a symposium focusing on creative ways that nurses are addressing the current health care environment. Sponsored by the Division of Nursing at the Hospital of the University of Pennsylvania and the University of Pennsylvania School of Nursing. October 26-27, 1986. For information contact: Dr. Constance M. Carino, Associate Professor/ Clinical Director, Psychiatric Nursing, Gates 11-HUP, 3400 Spruce Street, Philadelphia, PA 19104. 